\title{
Forest, water and people: The roles and limits of mediation in transforming watershed conflict in Northern Thailand
}

\author{
Ahmad Dhiaulhaq ${ }^{1,2, *}$, Kanchana Wiset ${ }^{1}$, Rawee Thaworn ${ }^{1}$, Seth Kane ${ }^{1}$, David Gritten ${ }^{1}$ \\ ${ }^{1}$ RECOFTC - The Center for People and Forests, Kasetsart University, Bangkok, 10903, Thailand; e-mail: \\ kanchana.wiset@gmail.com, rawee@recoftc.org, seth.kane100@gmail.com,david.gritten@recoftc.org \\ ${ }^{2}$ Crawford School of Public Policy, Australian National University. Stanner Building, 37 Lennox Crossing, \\ ANU, Canberra, ACT 2601; e-mail: ahmad.dhiaulhaq@anu.edu.au \\ * Corresponding author
}

\begin{abstract}
This study focuses on watershed management in Northern Thailand, where conflict over forest, land and water-use is a prevailing problem. A characteristic of watershed conflicts is that they are often multifaceted and involve multiple stakeholders with different interests and values, consequently requiring conflict management approaches that are sustainable in their outcomes, including addressing the underlying causes of the conflicts. Drawing from a case study in Mae Tia Mae Tae watershed in Northern Thailand, this study explores how mediation by external third party can contribute to the transformation of conflicts in the watershed and how the broader institutional contexts in which the conflict is embedded shapes the mediation outcomes. The study suggests that co-creation of mutual understanding and recognition of each party's socio-cultural differences, including land-use practices, are critical in building trust and in how conflict transformation processes moved forward. Moreover, the ability of the mediator in facilitating the establishment of a deliberative institution (i.e. a watershed network committee) and agreed rules on forest utilization were also critical in maintaining long-term collaboration in the watershed and potentially preventing other conflicts arising in the future. Some issues, however, may threaten the continuity of the cooperation and sustainability of peace in the watershed, including the lack of structural reform that formally recognizes local people's rights, insecure land tenure, and the absence of legal recognition for the watershed network committee as a legitimate mechanism for watershed decision making. The paper discusses these findings by comparing it with those from our previous studies in other locations (Cambodia, Indonesia and Western Thailand) to strengthen the insights from Northern Thailand. Finally, the research puts forward some recommendations for reforms and to strengthen the use of effective mediation, to achieve transformative outcomes, in conflicts of this nature.
\end{abstract}

Keywords: Watershed management; forest conflict; mediation; conflict transformation; Thailand

\section{Introduction}

Northern Thailand is known for its rich natural environment, including dense forests and high levels of biodiversity. The mountainous region is also known for its cultural diversity, as it is home to both ethnic northern Thais, who mainly live in the lowland areas and minority hill-tribes (e.g. Karen and Hmong) who live mainly at higher elevations (Uhlig, 1980; Wittayapak and Dearden, 1999). There is a great deal of pressure on these ecologically and culturally rich landscapes, as well as a large amount of contestation between various stakeholder groups. Numerous publications have shown that conflict often occurs in watersheds in Northern Thailand between the hill-tribes minority groups living at higher elevations and forest authorities (Laungaramsri, 2000; Tungittiplakorn, 1995) as well as between these minority groups and communities (e.g. farmers) residing lower down the watershed over land-use practices and water management (Wittayapak and Dearden, 1999; Laungaramsri, 2000). The tension has also been driven by other social and political issues such as conservation movement, social prejudices among different ethnic groups, perceived illegal immigration and efforts to eradicate opium poppy cultivation in the Northern 
highland areas (Hares, 2009). For example, upstream ethnic minorities are largely perceived by forest authorities and the lowland communities to be responsible for uphill forest degradation due to their settlement and land-use practices (e.g. swidden agriculture), negatively affect downstream communities (Laungaramsri, 2000; Hares, 2009).

Conflict over watershed management is a common issue in many countries around the world (e.g. Steinberg and Clark, 1999; Imperial and Kauneckis, 2003; Church, 2009; Tungittiplakorn, 1995), reflecting the plethora of stakeholders with differing views, values and interests (e.g. sociocultural, political, environmental and economic) over the management of forest, land and water resources. These characteristics can also explain why watershed conflicts are usually complex; they often involve multi-parties or multiple stakeholders, often with a large number of constituents with multiple objectives, diverse socio-economic status, culture, ethnicity and values. These types of conflicts require conflict management approaches that are sustainable in their outcomes, including addressing the underlying causes of the conflicts.

While studies have shown that natural resource conflicts in certain circumstances can bring positive impacts such as strengthening collective action, opening a space for communication and negotiation between the conflict parties, and increasing awareness of the need to clarify and address tenure problems (de Koning et al., 2008; Yasmi et al., 2009, 2013; Dhiaulhaq et al., 2014b, 2015), in most cases forest conflicts predominantly bring negative consequences (economic, environmental and social) such as triggering destructive behaviors, anxiety, fear, forest depletion, and reduced income (Yasmi et al., 2009, 2013). Consequently, effective conflict transformation mechanisms are crucial to ensure that conflicts have constructive outcomes.

This study is concerned with watershed in Northern Thailand, where forest and land conflict is a prevailing watershed management problem. While several studies have been conducted on watershed conflicts in Northern Thailand (e.g. Buergin and Kessler, 2000; Laungaramsri, 2000; Delang, 2004; Hares, 2009), their focus, however, is mainly on examining the causes, intensity, impacts, and actors in watershed conflicts. Research on how these conflicts in Northern Thailand and watershed conflicts in general are addressed is underdeveloped (Dhiaulhaq et al., 2015). This study intends to address these gaps. Drawing from a case study in Mae Tia Mae Tae (MTMT) watershed in Northern Thailand, this study explores whether third-party mediation can contribute to the transformation of conflicts in the watershed. This entails examining what processes lead to positive outcomes and how broader institutional structures or contexts shape the mediation outcomes. Additionally, as this study is part of a regional study (in Cambodia, Indonesia and Thailand) analysing the role and effectiveness of conflict mediation in transforming forest and land conflicts, insights from our other cases (Dhiaulhaq et al., 2014a, b, 2015) are also presented and discussed to assess similarities and differences.

\section{Analysing conflict mediation through a transformative mediation framework}

Mediation can be understood as an assisted negotiation process facilitated by a third party (or parties) which aims to assist the conflicting parties to find mutually acceptable solutions, including by addressing the underlying causes of the conflict (e.g. Wall et al., 2001; Engel and Korf, 2005). Many scholars believe that the use of mediation, as a form of alternative dispute resolution (ADR), can enhance procedural justice by devolving decision-making to the conflicting parties, encouraging equality among parties, as well as minimizing coercion, for example through legal measures (e.g. Rubenstein, 1999). This paper follows those scholars who view the mediation field as diverse and pluralistic-not all mediators follow the same practices and objectives (e.g. Augsburger, 1992; LeResche, 1992; Bush and Folger, 2005). As an example, some authors have pointed out that mediation in a Western and non-Western culture can take different pathways or strategies in addressing conflicts (Augsburger, 1992; Callister and Wall, 2004; Lee and Teh, 2009).

Within the mediation field, transformational approaches are increasingly prominent for both 
practitioners and scholars. Conflict transformation aims not only to end or settle conflicts but also to create a major shift in the quality of interaction and promote conditions that create long-term constructive relations (Mitchell, 2002; Reimann, 2004; Bush and Folger, 2005). The transformative approach is often put in contrast with 'problem-solving' or 'settlement' approach which emphasizes generating a 'resolution' in order to settle the conflict. In contrast, the transformative mediation model does not put resolution or consensus as their immediate priority.

Mitchell (2002) provides an excellent review of different views within the 'conflict transformation school'. Although different scholars stress different aspects of what conflict transformation transforms, she argues that most seem to agree that the core aspect that needs to be transformed includes changes at the micro (i.e. personal and interpersonal or relationship level) and macro level (i.e. structural level). Similarly, Vayrynen (1991) argues that conflict transformation may involve: 1) Actor transformation, which involves major internal changes within the conflict parties and their relations with others; 2) Issue transformation, which involves changes in the political issue of the conflict, such as finding common ground among the parties; 3) Rule transformation, which involves changes in the norms shaping the parties' interactions; and 4) Structural transformation, which involves changes in the structural issues that cause the conflict. We use these frameworks to structure our analysis in this article.

Additionally, in investigating the 'micro-level' conflict mediation process and outcomes, we also use Bush and Folger's (1994; 2005) 'transformative mediation' framework to guide our analysis. The role of the mediator in this model is expanded to assist conflicting parties to shift towards more positive interactions through, and characterized by two key aspects: empowerment and recognition. Empowerment here defined by Bush and Folger as improving the capability of the conflict parties to handle and make better decisions on their conflict problems. This includes the ability to clarify their goals, options and preferences as well as to communicate and negotiate these with other parties. Regarding recognition, it includes the willingness of a party to acknowledge, respect and empathize with the perspectives, views, situation and experiences of others. Bush and Folger (2005) argue that empowerment and recognition are the keys to transformative mediation because when these occur in conflict, the quality of the interaction will transform from destructive to constructive.

Moreover, in this article, we also examine the "macro" perspective of the socio-political context that shapes the conflict, mediation processes and outcomes, thereby providing a more comprehensive examination of the mediation. The socio-political context may include power relations, institutional structure governing forests, discourses, economic interests, and political and cultural environments (e.g. Peluso and Watts, 2001; Raitio, 2012; Zachrisson and Lindahl, 2013). This is mainly because mediation and conflict do not occur in a vacuum. Lederach (1997) suggested that the goals of conflict transformation include enhanced wellbeing, interdependence, and justice, and where possible strive to change and address systemic factors and policies that underlie conflicts. This study will assess whether the processes and outcomes of mediation in the case study site satisfy these various definitions and goals of conflict transformation.

\section{Methodology}

The empirical focus of this article is on Mae Tia Mae Tae (MTMT) watershed in the Northern Thailand. The findings presented in this study are drawn from data gathered by authors in 2012 as part of a regional research project examining forest-conflict mediation in Southeast Asia (Dhiaulhaq et al., 2015). The study was designed as a qualitative research and employed several methods of data collection, including: 1) semi-structured interviews; 2) focus group discussions (FGDs); and 3) field observations in the MTMT watershed. Semi-structured interviews were conducted in August 2012 involving 54 key informants (37 males and 17 females) representing the conflict and mediation stakeholders, including members of highland and lowland communities, 
mediator team (i.e. the Sustainable Development Foundation, SDF), government staffs and national park officers. Additionally, three FGDs [with representatives of the mediator team, the lowland and highland communities, and members of the watershed committee] were also conducted. The field observations were also undertaken to understand local land use and livelihoods pattern, as well as conservation activities in the watershed. The analysis also included the collection and review of reports, newspapers, and journal articles. Some of the findings from the 2012 fieldwork were also included in the earlier regional-level article (Dhiaulhaq et al., 2015). Further interview with the SDF team was conducted in June 2017 to get some updates on the findings from the earlier fieldwork, including examining the impacts of the mediation.

MTMT watershed is a sub-watershed of larger Mae Krang watershed. It is located in Chom Thong District, about 2-3 hours drive from the provincial capital of Chiang Mai. It is a large (approximately 14,800 hectares) mountainous landscape with an altitude range of $300-1,740$ meters. Approximately 84 percent of the land in this watershed $\left(148 \mathrm{~km}^{2}\right)$ is forest: hill evergreen, dry dipterocarp, and mixed deciduous. Most of the watershed is government-designated protected areas, which includes Ob Luang National Park, Doi Inthanon National Park and National Forest Reserved area. It is a source for the Mae Tia and Mae Tae Streams which feed the Ping River. The area is inhabited by various communities in 23 villages scattered in three sub-districts (Doi Kaew, Sob Tea, and Mae Soi) in Chom Thong District. It is home to three major ethnic groups: Hmong (one large community), Paka-Kyaw--also known as Karen (five communities), and Northern Thai communities who live in the downstream of the watershed (17 communities). MTMT watershed is also home to at least 147 wildlife species which can be divided into four groups: amphibians ( 9 species), reptiles ( 23 species), birds ( 97 species) and mammals (12 species). Some of them are rare wildlife species protected by the Government based on 1992 Wildlife Preservation and Protection Act B.E. 2535.

\section{Results}

\subsection{The conflict in Mae Tia Mae Tae watershed}

The case study exemplifies the complex nature of conflict over watershed management in Northern Thailand; it involves multiple parties often with differing interests and values. Several social, environmental and economic changes in the area directly and indirectly affected relationships between the upland communities, lowland communities and forest authorities, leading to conflict between these actors (Figure 1). 


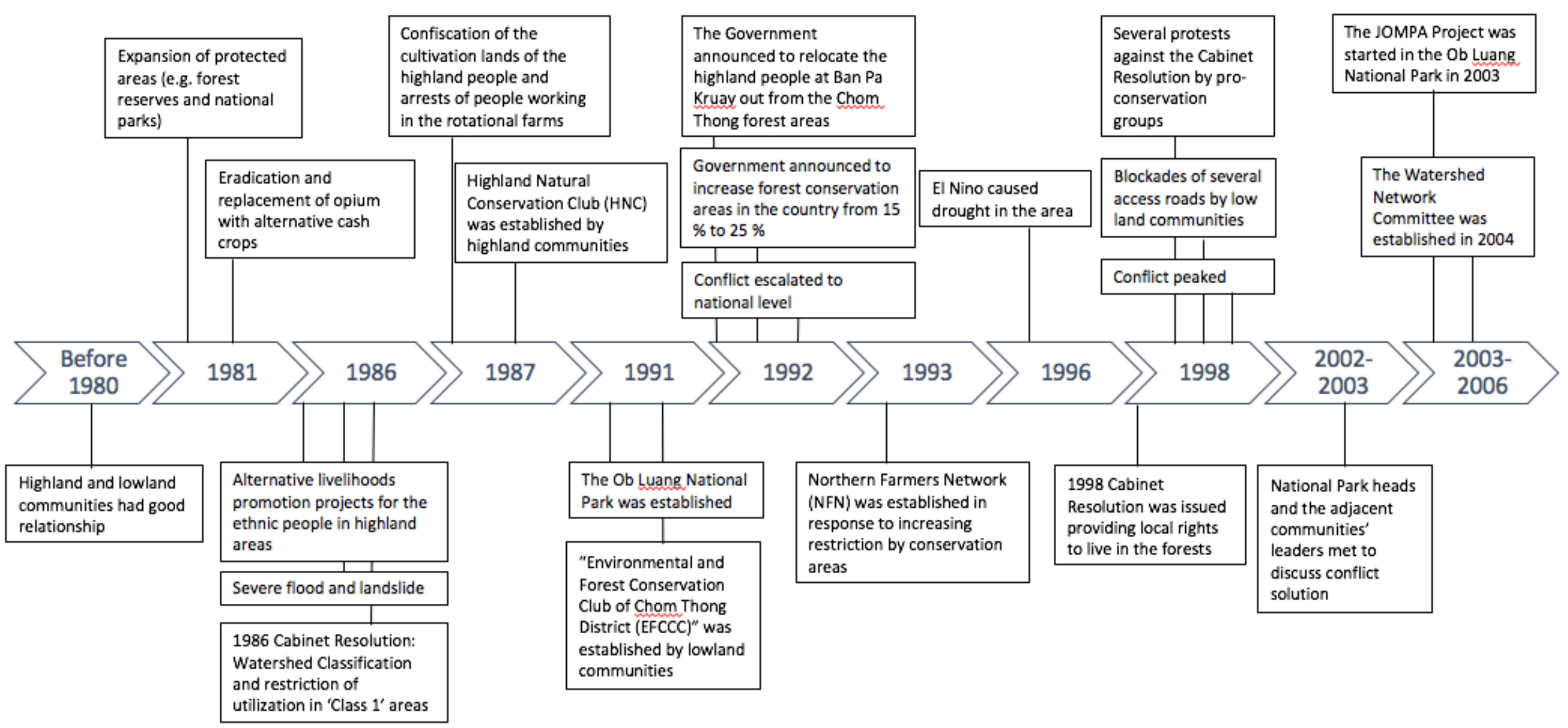

Figure 1. Timeline of key events related to conflict in Mae Tia Mae Tae Watershed 
During our fieldwork, both upland and lowland communities, especially the elders, were able to recall that both groups of communities had good relationships in the past (before the 1980s), indicated by joint-agricultural activities and substantial trade in forest and agricultural products. Changes in livelihood, water and land use patterns (Figure 1) gradually change this relationship and contribute to the emergence of the MTMT watershed conflict (Bonell and Bruijnzeel, 2005), especially after the State-led opium substitution programs starting in the 1980 s encouraged cash, mono-crop agriculture (e.g. cabbage and other vegetables for upland communities). This coincided with many lowland communities converting rice fields to Longan (Dimocarpus longan) plantations to earn more income. The changes in these land-use practices, such as growing cabbage and longan, requires more water creating competition for resources, particularly in the dry season. This dynamic was particularly pronounced in the 1996 - 2001 period, which saw regular droughts and increased inter-communal tensions.

Additionally, state territorialization (Vandergeest and Peluso, 1995) and exclusionary conservation policies were also responsible for the escalation of conflict in MTMT watershed. During the 1980s and 1990s, partly due to the heightened concern for environmental conservation as a result of rapid forest degradation, state actors zoned large areas of forest and land in the Northern Thailand as protected areas. In 1981 and 1991, for example, the Thai Government extended the boundaries the Doi Inthanon National Park and established Ob Luang National Park (OLNP) respectively. These protected areas covered large parts of the MTMT watershed, including parts of cultivation lands of the highland communities. Additionally, in 1986, the government also released a Cabinet Resolution establishing the Watershed Classification System, which designated most mountainous areas in Northern Thailand as Watershed Area Class 1 (WSC1), prohibiting natural resource extraction and human settlements ${ }^{1}$. These regulations directly affected highland communities who have been living in the mountainous forest areas for generations. Conflict incidences arose when the state territorialization was strictly enforced, with the exclusion of local inhabitants. Upland communities reported that there were incidences where many highland farmers were arrested due to their cultivation activities and destruction of the community member's crops by National Park officials.

The exclusionary approach was also proposed by some 'dark green' conservation NGOs operating in the area. Interviewed communities, especially in the upland, said that Conservation movement promoted by some NGOs exacerbated the conflict due to its tendency to recommend resettlement of the upland ethnic minorities to other locations as a solution to preserve the headwater and overall watershed area, and to maintain the water supply to the lower plain (see also Laungaramsri, 2000). The reason for relocation was largely influenced by the perception that the ecological problems in the downstream area were mainly caused by the upland ethnic minority communities settling and cultivating the headwater areas in the upstream (Laungaramsri, 2000). The movement rapidly received significant support from downstream villagers who increasingly needed water for their expanding mono-crop agriculture, and have complained about water shortages in their orchards and paddy fields (Forsyth and Walker, 2008). In the 1990s some lowland communities also formed a conservation group called Environmental and Forest Conservation Club of Chom Thong District (EFCCC) that also advocated for relocating highland communities from the forests. These NGOs were able to gain significant social support amongst lowlanders. In that period, the government passed the 1998 Cabinet Resolution acknowledging certain hill tribe forest rights, including rights to remain staying in the forest which the 'dark green' conservation NGOs and lowlanders perceived it as a deforestation and forest encroachment risk (Yamaguchi, 2006).

In response, highland communities also established their own group called the Highland Natural Conservation Club in Chom Thong District (HNC). Their movement was supported by local

\footnotetext{
${ }^{1}$ The watershed classification in Thailand is identified into 5 zones with the first (WSC1) and the second (WSC2) preserved as protection and commercial forests respectively and the rest (WSC3-WSC5) can be used for agricultural and other purposes with appropriate conservation and mitigation measures (See Tangtham 1996).
} 
NGOs, such as the Inter Mountain Peoples Education and Culture in Thailand Association (IMPECT), which worked primarily with ethnic minority groups.

In the late 1990s, the conflict between highland and lowland communities escalated, peaking in 1998 when lowland communities protested by obstructing several main roads to restrict highland community transportation. The roads blockade, which lasted about three months, caused serious inconvenience, especially for the highland communities. Economic impacts were felt by both parties, as travel and trade were impeded. Some schools were closed on occasion, and protesting took time away from the fields and other livelihood activities. In response to the blockade, the highland group, represented by HNC, undertook several mass protests at the local district and provincial government offices. The conflict eventually garnered significant attention, including from national news media. This conflict case was also used by the 'dark green' conservation NGOs to support their cause against the Community Forest Bill in the national level debate (Delang, 2004).

The conflict had many negative impacts, including disharmony and division within and between communities, including depression, fear, and violence, especially when the conflict was at its peak; with livelihood implications for both highland and lowland community members. During the conflict, for example, some lowland communities erected fences painted with red, white and blue colors - representing Thailand's national flag, causing the highland communities to perceive that they were considered unlawful non-Thai immigrants. One of upland villagers, for example, explained what he felt when he saw the fences: "I felt that we are not considered Thai people anymore. I was so upset because the poles' fences were made and painted with the color of Thai flag. At that moment, I felt that they thought that we are alien residents, like Burmese immigrants." As a result of the tensions, highlanders who live in the lowland areas could not visit relatives in the highlands. Highland communities also always prepared weapons, as they feared they would be ousted from their lands by force.

\subsection{The process of conflict transformation}

\subsubsection{How the process was initiated}

There were a number of informal attempts to address the conflict in the watershed. In 2002, for example, the head of OLNP together with the leaders of communities living in and next to the National Park area, for example, organized a discussion to find possible solutions to the conflict. In 2003, the Office of Natural Resource and Environmental Policy and Planning (ONEP), a government agency, organized a forum, with the support of key agencies in the area, i.e. Doi Kaew Tambol Administration Office and Sustainable Development Foundation (SDF). The forum invited the leaders of both upland and lowland communities to discuss the conflict issues and gave an opportunity to the community leaders to express their concerns and exchange information.

The attempt to address the conflict in a more systematic way through mediation was initiated when a local NGO, the Sustainable Development Foundation (SDF), started a project promoting joint management in protected areas (JOMPA project) in the OLNP in 2003. Initially, SDF did not focus on managing the conflict because their main objective was to promote participatory and collaborative processes in natural resource management. However, SDF discovered that the conflict intensity in the area hindered cooperation between the upland and lowland communities in managing their forests. SDF also realized there was a lack of actors who could act as an intermediary or a neutral party who can mediate the conflict.

In this regard, as part of the JOMPA project, SDF team conducted a preliminary assessment of the conflict, including undertaking a stakeholder analysis, identifying the main issues, and assessing the potential for mediation. SDF strategically used its prior relationships with the local communities from their extensive experience in the area and throughout Chiang Mai province. To 
approach the conflict parties, SDF used both formal and informal methods, such as talking individually to community leaders. Then the SDF identified key persons who would work with them in the processes of addressing the conflict and build collaboration among MTMT stakeholders. The upland and lowland communities eventually agreed to participate in the processes facilitated by the SDF in order to achieve these objectives and address their conflicts together.

In this regard, different to conventional mediation where a mediator is normally appointed by the conflict parties, in MTMT case, the SDF staffs were the ones who proactively approached the conflict parties, as part of their efforts to develop collaborative forest management in the area. The leader of SDF explained that the aim of the mediation was not only to resolve the conflict but also to build long-term collaboration in the watershed management; so that both parties could manage and mutually benefit from the natural resources in the MTMT watershed. He also explained that: "We focused on facilitating collaboration processes and the setting of long-term common goals together among the villagers, [because] when collaboration increases, conflict will also decrease." In total, the conflict mediation process facilitated by the SDF took more than three years (Figure 1), including some stages presented in the following sections.

\subsubsection{Actor and issue transformation}

The study suggests that co-creation of mutual understanding between the conflicting parties and recognition of each party's socio-cultural differences, including land-use practices, are a critical foundation for building trust and serve as a prerequisite for conflict transformation processes to move forward. To achieve this, at the initial stage, the mediator team, supported by the local government (the sub-district administrative organization, TAO) organized several meetings attended by conflict stakeholders. In these initial meetings, the mediator facilitated the representatives of upland and lowland communities to share their concerns and problems. The aim was to clarify the issues and create a mutual understanding and trust between parties. One of the villagers from the lowland recalled that in this first meeting "many exchanges of arguments and blaming to each other occurred in that meeting which SDF tried to mediate."

Additionally, exchange visits were also conducted between representatives of lowland and upland communities. The mediators also used videos as a tool to collect information about each party's culture and land-use practices. The videos showing the livelihood systems of both upland and lowland communities, including interviews with influential people in the area, were also shown to both communities to improve mutual understanding about other parties' culture and land-use practices.

As results of these processes, a change in understanding and perception about other parties' culture and livelihood patterns constituted important milestones for moving forward in addressing the conflict. These also led to a change of attitudes towards one another-from one of recrimination to mutual understanding and respect. One of lowland villagers, for example, describes this change in their interaction: "The relationship now has improved. The lowland people now can go up to the upland areas, and the upland people will greet and invite us for meals. During the conflict, they would not even talk to the lowland communities, and they would not even give water to us."

One of the most important processes facilitated by the mediators was the creation of the MTMT watershed network committee, as a platform for discussing conflict and other watershedmanagement issues. During one of the joint-meetings between upland and lowland communities, the mediator team proposed an idea of forming an MTMT watershed network committee as a platform for lowland and upland people to exchange information and discuss their problems in managing the watershed. The idea of establishing MTMT watershed network committee was also to ensure that any potential issues that might lead to conflict in the future could be addressed and 
therefore could contribute to the sustainability of a peaceful environment and maintain long-term cooperation. Although the initial idea to establish the network committee came from the mediator team, the decision was agreed and made by both groups of communities, and endorsed by the NP officials. The network consisted of representatives from 23 villages (two representatives from each village) in the upland and lowland areas and was supported by the head of OLNP. One of committee members from an upland village reflected: "If we still blame each other, we cannot work well, and if all people cooperate and are discipline in using forests and water, the problems will not happen. At least, if a problem comes up, we can still solve it through our cooperation."

However, the mediators consider that although the watershed committee offers a deliberative and problem-solving mechanism and participation in watershed management, it is currently still an informal local platform without a legal basis, raising a question of the legitimacy of the decisions made. This issue will be discussed in the discussion section.

\subsubsection{Rule transformation}

Once the watershed network committee was established, in order to address the contested boundaries, a participatory land demarcation process was conducted to map the land utilized by communities, including the settlement, agriculture and protected areas. The demarcation of the boundaries involved representatives of both upland and lowland communities, the National Park and the mediator team. To ensure the effectiveness of the participatory processes, before this demarcation process, the mediator team trained all representatives and the watershed network committee members to use GPS as well as survey and mapping techniques, so all parties could work and communicate in the same technical 'language'. Based on the results of the participatory demarcation process, the mediators converted the result of land demarcation into computerized maps (i.e. GIS). Considering the wide area, the number of issues and stakeholders involved, the demarcation process took over three months. The boundary maps were edited three times until all parties agreed.

Once the boundaries were clarified, the parties started a discussion on establishing rules and regulations on land and forest resource utilization in the watershed, facilitated by the mediator team. These rules were established through participatory processes-the mediators invited the communities' representatives to discuss the rules and regulations so they would fit within the existing local rules and context of each community, including their local or traditional practice of forest management. In order to gain recognition of the results of the land demarcation and the agreed rules, the mediator team proposed that these agreed rules be presented to relevant organizations such as the NPs and local governments for endorsement.

The agreement on these rules helped both upland and lowland communities understand their rights and responsibilities in managing and utilizing the natural resources in the area. As the rules were the result of participatory process, it contributed to the compliance to the rules, including preventing encroachment. For the government, the mediation supported the work of the NP officers in protecting the forest. A park ranger reflected that the success of mediation and compliance with the rules and regulations by the communities made the work of the national park officers easier. He gave an example that now, when the local communities meet the NP officers they are willing to talk and sometimes offer them meals. In cases where someone breaks the rules, the officers let their leaders address the issue first according to the communities' rules, with the national park officers only acting if the communities cannot manage the cases themselves.

Following the conflict's de-escalation, the mediators started building collaborative and institutional capacity of all communities in managing the watershed, including conserving forest and developing alternative livelihoods sources. The communities and mediator team ensured that conservation activities aligned with the local culture and beliefs of both groups of communities. For example, the lowland communities conducted forest ordinations and water ceremonies, and 
the highland communities worshipped forest and water spirits while inviting representatives to participate in each other's activities. Moreover, both communities also worked together to make forest fire breaks supported by the local government.

\subsubsection{Limited structural transformation}

Interviewed villagers said that the boundary demarcation process, including clarification and demarcation of land functions (e.g. agriculture, protected areas) resulted in a better sense of security and recognition of their rights towards land use, at least at the local level. This was partly the result of participatory boundary demarcation being acknowledged by the NPs and local government staffs. The agreed boundaries also contributed to the reduced access restriction to forest resources in agreed locations. After the land demarcation and clarification of the boundaries, villagers said that they were able to continue utilizing the land for agriculture and other income generation activities without disruption. The upland communities, for example, now can grow their crops throughout the year without worrying about being arrested by NP officers. Additionally, the agreed rules, which include agreement on forest and water management, also ensures that both communities have a better distribution of water for household consumption and agricultural activities contributing to income security.

However, despite these improved situations, the mediators and communities realized that the agreed land demarcation and maps could not be used as a legal basis for communities' land rights, causing insecurity for forest dwellers. This is because the State Law, particularly the NP Act (1962) strictly prohibited settlement and agricultural activity in NP areas. In this regard, change at a larger scale (e.g. at the national level), in terms of securing legal recognition of local land rights is still limited. This also shows the limits of mediation in addressing conflict which involve structural and public policy problems, particularly in the forestry context. Up until the time of writing of this article, the SDF is still facilitating community efforts in gaining a legal right from the Department of National Parks, Wildlife and Plant Conservation (DNP).

A stronger, formal recognition of both the local land rights and the watershed network platform are considered important by the mediators and communities to provide a more secure situation, especially regarding land tenure. The mediator mentioned that in a situation where, for example, there is a leadership change in the protected areas, the policy might also change. Moreover, a new leader may not have the same level of awareness of the conflict issues in the area, which may make him/her make a policy that goes to a different direction. The formalization of recognition is to ensure that whoever lead the NP, s/he will promote similar participatory policy and recognition of local land rights.

\section{Discussion and concluding remarks}

\subsection{The need to enhance recognition}

In this study, we have sought to understand the role of external third-party mediation to facilitate the process of addressing a watershed conflict, its implications for conflict transformation and the challenges it faced. The findings presented in earlier sections suggested that an external third-party mediation has the potential to play an important role in opening up dialogue among the conflict parties and changing conflict interactions among watershed stakeholders, especially when the parties could not address the conflict by themselves.

The study, however, found that despite some improvements in the quality of interaction among the conflict parties during and after the mediation process (actor and local rule transformations), the mediation suffers several limitations, especially at the higher and structural level. An important limitation in the mediation in MTMT is that some of the goals to change the structural issues relating to recognition of rights, that became the underlying cause of the conflict, have not been fully achieved. For example, although after the participatory land demarcation the 
local communities were able to continue to live and do their agricultural activities, they still do not have a strong legal basis for their land rights. The fact that some of their agricultural plots are within the NP area, it means they are still regulated under the 1961 NP Act (Government of Thailand, 1961) which prohibits settlement, forest product extraction and agricultural activity in NP areas. Patel et al. (2013) argue that access to forest resources is essential in meeting subsistence needs of local stakeholders, and therefore any policies or practices that strictly limit local access to forest resources will lead to conflict. In this regard, the study suggests that change at a larger scale (e.g. at the national level), in terms of securing legal recognition of rights (e.g. rights to access, use, manage, live in the forest) is still needed and should be facilitated by Thai law. If the rights of local people over forest resources is not secured, the conflicts may reoccur in the future.

This study therefore shows the limit of mediation in addressing conflict which involves structural and public policy problems, particularly in the forestry context. A similar issue was also found in other research sites including in Kanchanaburi, Western Thailand (Dhiaulhaq et al. 2014b, 2015), where the agreement between local communities and National Park could not be used as a strong legal basis for their land tenure although it eventually allowed the communities to stay and continue their agricultural activities (Dhiaulhaq et al., 2014b, 2015). However, as de Koning et al. (2008) point out, processes of getting recognition of rights in the context of forest management are political rather than technical. They are subject to a growing competition and may also face opposition from vested interests in land and forest resources (e.g. from authorities in charge of forest and conservation).

Based on the insights from the MTMT mediation, at the conceptual level, the paper would suggest expanding Bush and Folger's (2005) concept and definition of recognition, to also include institutional recognition, for example, recognition of rights by the state. Bush \& Folger's definition of recognition, which includes the willingness of a party to acknowledge, respect and empathize with the perspectives, views, situation and experiences of others, may not be enough when the conflict involves structural or public policy issues. This paper would argue that in the case such as MTMT watershed, recognition should be beyond the level of actors (i.e. interpersonal) but also include the institutional and structural level. Additionally, as Martin et al. (2016) suggest, part of improving recognition in conservation is to also ensure equitable engagement and influence over decision-making, for example by integrating local actors and their ways of knowing, valuing and managing resources in conservation management.

\subsection{The need to strengthen the capacity}

Bush and Folger (1994; 1995) highlight the importance of 'empowerment', defined as improving the capability of the conflict parties to handle and make better decisions on their conflict problems, as an important condition for conflict transformation. This includes the ability to clarify their objectives, options and preferences as well as to communicate and negotiate these with other parties. One of the important achievements of the mediation process in the MTMT case was the ability of parties to agree on and to put in place an institution or procedure that can be used as a platform to address, maintain and prevent conflict in the future (i.e. watershed network committee). This type of institution, according to Mitchell (2002) is one of the important mechanisms needed to ensure that conflict transformation can be sustainable. Based on studies on watershed partnership in various countries, Leach and Pelkey (2001) argue that forms of partnership like the watershed network committee can create opportunities for all stakeholders to communicate before problems or conflicts occur. Moreover, by enhancing communication and building consensus, such partnerships may help prevent unnecessary disruptions and tensions in water and forest management as well as community activities and productivity (e.g. agriculture, business) while generating more technically sound management plans and policies that draw upon the variety of expertise and knowledge within the community and beyond (Leach and Pelkey, 
2001). This discussion platform, although it is not a formal institution, can also potentially promote informal governance processes in the area and bolster local forest management with positive and sustainable outcomes (Mansourian, 2017). For example, in this case, some impacts included enhanced local awareness of forest conservation, the revision of rules and regulations on forest use which appropriate for the multi-stakeholders, and joint conservation activities between highland and lowland communities.

The study suggests that there is still a need for a formal, legal recognition (e.g. from the government) of the MTMT watershed network committee as an institution and platform for decision making over watershed management. This legal recognition would hopefully be able to strengthen the legitimacy and sustainability of this mechanism in addressing any issues and conflict in the future. A legal status recognition would also help ensure their long-term existence, legitimacy and credibility, for example in finding financial support for their programs. Moreover, in order to ensure the continuity of the network committee this paper would recommend that the relevant government agencies who work in the area to establish support systems or mechanisms that maximize the function of the watershed network in the watershed management. With sufficient support, the communities and mediators hope to create it as a platform for conflict management.

The mediation in MTMT case has some special characteristics in terms of the nature of conflict parties (e.g. multi-party, indigenous people) and the nature of the conflict issues (e.g. protected area, conservation movement) involved. One of the differences between the MTMT case and other case studies that were part of this research project (Dhiaulhaq et al., 2015) is that conflict mediation in MTMT watershed was comparatively more complex and consequently require a longer time (more than three years). It is understandable considering the conflict involved various issues (i.e. direct and underlying causes of conflict), actors and interests that needed to be addressed. The conflict in MTMT watershed involved multiple stakeholder groups (the upland and lowland communities in 23 villages spread over the upland and lowland areas, as well as NP authorities). This is relatively different to, for example, other case studies of forestry and oil palm plantation cases in Indonesia (Dhiaulhaq et al., 2014a, 2015) where the primary conflict parties (and mediation process) involved two primary parties-between a plantation company and local community. Analysing mediation with this conflict characteristic offers valuable insights, especially in comparison to mediation in two-party conflicts.

As mentioned in other literature (e.g. Lesnick \& Ehrmann, 1987), mediators in multi-party disputes face challenges of conducting mediation processes mainly due to the large number of parties and interests that may be dispersed across a broad geographic area. The long process also means that the mediation requires more resources (human, financial). It is fortunate that the mediation of the MTMT conflict is part of a participatory forest management project funded by international donor organizations. Without such support, it is difficult to imagine the long mediation efforts could be effectively undertaken.

Additionally, this study suggests that mediation in MTMT conflict is different to a conventional form of mediation. In this case, for example, rather than a stand-alone conflict mediation process facilitated by a professional mediation organization or mediators, mediation of the conflict in MTMT is part of a participatory forest management project facilitated by an NGO. Our earlier studies found that this (NGO facilitating mediation) is not uncommon in forest conflicts in Southeast Asia. In Indonesian case (Dhiaulhaq et al., 2014a), an NGO who facilitated the mediation process between a plantation company and local community was NGO activists who at first assisted and advocated in the interest of the community, and then with agreement of the company, eventually become mediators of the conflict.

The SDF raised some recommendations for improving the mediation process. First, the mediator should gain formal, legal support from the authorized government agencies for effectively addressing forest conflicts; so, the impact would be more concrete and sustainable, 
especially when the conflict involves State forest areas. Second, besides promoting a participatory process in forest management, improving the quality of life of local people should be conducted simultaneously (in addition to conflict transformation efforts). This would help to provide alternative livelihood opportunities for local communities instead of depending solely on forest, reducing tension between local livelihood and conservation objectives. Third, the mediator should try to link or incorporate the implementation of the results of the mediation process into local government plans so that all activities would be more sustainable. Finally, if the watershed network is promoted as a platform for conflict management, local communities especially the watershed network committee, should be supported in improving their natural resource and conflict management capacities.

At the practical level, our results suggest that in order to effectively address the complex and multidimensional nature of watershed conflict, mediators need to take a variety of roles, therefore requiring skills and capacities which enable them to take these roles. This includes facilitating effective communication and negotiation, building trust and when necessary, proposing alternative solutions. The mediators also need to understand the local and national contexts of watershed management. According to the SDF mediators, these skills were acquired from their previous experiences in facilitating and promoting participatory processes in natural resource management in other areas, not from a formal training on conflict management or mediation, which were still rarely available at that time. However, while the mediators' skills are one of the key factors in successful mediation, the number of capable mediators to address conflict over natural resources is still limited. This is in line with the earlier study findings that the number of mediators in Asia is still relatively low (Yasmi et al., 2010; Dhiaulhaq et al., 2015). In this regard, this paper would suggest the importance of developing the capacity not only of the mediators but also the conflict transformation capabilities of key watershed stakeholders in general (i.e. community, government, National Park authorities) on how to prevent, address and deal with conflicts through targeted training programmes on conflict transformation. This is particularly important because conflict mediation is sensitive and if done improperly can exacerbate conflict situations (e.g. Kerr, 1954).

Finally, the study shows that the use of 'conflict transformation' framework can help practitioners understand the opportunities and gaps in the mediation process. This study would also recommend that future research should also cover cases in which mediation attempts failed and why. Learning from failure may help us understand more about the fundamental attribution of errors (whether mediators' strategies or external factors outside their control led to the failure) and more about the limitation of mediation in transforming forest and land conflict. Additionally, a careful assessment of the impacts of mediation on conflict transformation is also needed, in order to provide stronger evidence on the role of mediation for transforming watershed conflicts.

\section{Acknowledgements}

The authors are grateful to the Swedish International Development Cooperation Agency (SIDA), the Norwegian Agency for Development Cooperation (NORAD) and the Swiss Agency for Development and Cooperation (SDC) for funding this research. Views in this article belong to the authors. We are indebted to the participants of the experts' workshop, those who took part in the interviews and FGDs as well as the anonymous reviewers for their constructive feedback on the earlier version of the article. 


\section{References}

Augsburger, D. W. (1992). Conflict mediation across cultures: Pathways and patterns. Westminster: John Knox Press.

Bonell, M., \& Bruijnzeel, L. A. (Eds.). (2005). Forests, water and people in the humid tropics: past, present and future hydrological research for integrated land and water management. Cambridge: Cambridge University Press.

Buergin, R., \& Kessler, C. (2000). Intrusions and exclusions: Democratization in Thailand in the context of environmental discourses and resource conflicts. GeoJournal, 52(1), 71-80.

Bush, R. A. B., \& Folger, J. P. (1994). The promise of mediation: Responding to conflict through empowerment and recognition. San Francisco: Jossey-Bass.

Bush, R. A. B., \& Folger, J. P. (2005). The promise of mediation: The transformative approach to conflict. San Francisco: John Wiley \& Sons.

Callister, R. R., \& Wall Jr, J. A. (2004). Thai and US community mediation. Journal of Conflict Resolution, 48(4), 573-598.

Church, J. (2009). Avoiding Further Conflict: A Case Study of the New York City Watershed Land Acquisition Program in Delaware County, NY. Pace Envtl. L. Rev., 27, 393.

De Koning, R., Capistrano, D., Yasmi, Y., \& Cerutti, P. (2008). Forest-related conflict: Impact, links, and measures to mitigate. Washington D.C., USA: RRI.

Delang, C. (2004). Living at the edge of Thai society: The Karen in the highlands of northern Thailand. London; New York: Routledge.

Dhiaulhaq, A., Gritten, D., De Bruyn, T., Yasmi, Y., Zazali, A., \& Silalahi, M. (2014a). Transforming conflict in plantations through mediation: Lessons and experiences from Sumatera, Indonesia. Forest Policy and Economics, 41, 22-30.

Dhiaulhaq, A., De Bruyn, T., Wiset, K., Thaworn, R., Gritten, D., Yasmi, Y., Soontornwong, S., Kritsanarangsan, S. (2014b). Transformative mediation, a tool for maximising the positives out of forest confict: A case study from Kanchanaburi, Thailand. Forests under pressure: Local responses to global issues, IUFRO World Series, vol. 32, Vienna: International Union of Forest Research Organizations (IUFRO).

Dhiaulhaq, A., De Bruyn, T., \& Gritten, D. (2015). The use and effectiveness of mediation in forest and land conflict transformation in Southeast Asia: Case studies from Cambodia, Indonesia and Thailand. Environmental Science \& Policy, 45, 132-145.

Engel, A., \& Korf, B. (2005). Negotiation and mediation techniques for natural resource management. Rome, Italy: FAO.

Forsyth, T., \& Walker, A. (2008). Forest guardians, forest destroyers: the politics of environmental knowledge in northern Thailand. University of Washington Press.

Government of Thailand (1961). National Park Act, B.E. 2504 (1961). Government of Thailand. 5 p.

Hares, M. (2009). Forest conflict in Thailand: Northern minorities in focus. Environmental management, 43(3), 381-395.

Imperial, M.T., \& Kauneckis, D. (2003). Moving from conflict to collaboration: watershed governance in Lake Tahoe. Natural Resources Journal, 1009-1055.

Kerr, C. (1954). Industrial conflict and its mediation. American Journal of Sociology, 230-245.

Laungaramsri, P. (2000). The ambiguity of" watershed": the politics of people and conservation in northern Thailand. Sojourn: Journal of Social Issues in Southeast Asia, 15(1), 52-75.

Leach, W.D., \& Pelkey, N.W. (2001). Making watershed partnerships work: a review of the empirical literature. Journal of water resources planning and management, 127(6), 378385.

Lederach, J. P. (1997). Building peace: Sustainable reconciliation in divided societies. Washington 
DC: United States Institute of Peace Press.

Lee, J., \& Teh, H. H. (Eds.). (2009). An Asian perspective on mediation. Singapore: Academy Publishing.

LeResche, D. (1992). Comparison of the american mediation process with A Korean-American harmony restoration process. Conflict Resolution Quarterly, 9(4), 323-339.

Lesnick, M. T., \& Ehrmann, J. R. (1987). Selected strategies for managing multiparty disputes. Conflict Resolution Quarterly, 1987(16), 21-29.

Mansourian, S. (2017). Governance and forest landscape restoration: A framework to support decision-making. Journal for Nature Conservation, 37, 21-30.

Martin, A., Coolsaet, B., Corbera, E., Dawson, N. M., Fraser, J. A., Lehmann, I., \& Rodriguez, I. (2016). Justice and conservation: The need to incorporate recognition. Biological Conservation, 197, 254-261.

Mitchell, C., 2002. Beyond resolution: what does conflict transformation actually transform?. Peace and Conflict Studies, 9(1), pp.1-23.

Patel, T., Dhiaulhaq, A., Gritten, D., Yasmi, Y., De Bruyn, T., Paudel, N.S., ... \& Suzuki, R. (2013). Predicting future conflict under REDD+ implementation. Forests, 4(2), 343-363.

Peluso, N. L., \& Watts, M. (Eds.). (2001). Violent environments. Cornell University Press.

Raitio, K. (2012). New institutional approach to collaborative forest planning on public land: Methods for analysis and lessons for policy. Land Use Policy, 29(2), 309-316.

Reimann, C. (2004). Assessing the state-of-the-art in conflict transformation: Reflecting from a theoretical perspective. In A. Austin, M. Fischer \& N. Redpers, eds. Transforming ethnopolitical conflict: The Berghof handbook. Berlin: VS Verlag fur Sozialwissenschaften.

Rubenstein, R. E. (1999). Introduction: Conflict Resolution and Social Justice. Peace and Conflict Studies, 6(1), 1-7.

Steinberg, P. E., \& Clark, G. E. (1999). Troubled water? Acquiescence, conflict, and the politics of place in watershed management. Political Geography, 18(4), 477-508.

Tangtham, N. (1996). Watershed Classification: The Macro Land-use Planning for the Sustainable Development of Water Resources. Paper presented at the International Seminar Workshop on "Advances in Water Resources Management and Wastewater Treatment Technologies", 22-25 July 1996, Suranee University of Technology, Thailand.

Tungittiplakorn, W. (1995). Highland-Lowland conflict over natural resources: A case of Mae Soi, Chiang Mai, Thailand. Society \& natural resources, 8(4), 279-288.

Uhlig, H. (1980). Problems of land use and recent settlement in Thailand's highland-lowland transition zone. In Conservation and development in Northern Thailand, ed. J. D. Ives, S. Sabhasri, and P. Vorurai, 33-42. Tokyo: United Nations University Press.

Vandergeest, P., \& Peluso, N. L. (1995). Territorialization and state power in Thailand. Theory and society, 24(3), 385-426.

Vayrynen, R. (1991) To Settle or to Transform? Perspectives on the Resolution of National and International Conflict, in R. Vayrynen, ed., New Directions in Conflict Theory. Thousand Oaks: Sage Publications.

Wall, J.A., Stark, J.B., \& Standifer, R.L. (2001). Mediation a current review and theory development. Journal of Conflict Resolution, 45(3), 370-391.

Wittayapak, C., \& Dearden, P. (1999). Decision-making arrangements in community-based watershed management in northern Thailand. Society \& Natural Resources, 12(7), 673691.

Yamaguchi, K. (2006). Scarcity and conflict of resources: Chom Thong water conflict. Bali, Indonesia: International Association for the Study of the Common Property.

Yasmi, Y., Guernier, J. and Colfer, C.J.P., (2009). Positive and negative aspects of forestry conflict: lessons from a decentralized forest management in Indonesia. International Forestry Review, 11(1), pp.98-110. 
Yasmi, Y., Kelley, L., \& Enters, T. (2010). Conflict over forests and land in Asia: Impacts, causes, and management. Bangkok, Thailand: RECOFTC.

Yasmi, Y., Kelley, L.C., \& Enters, T. (2013). Community-outsider conflicts over forests: Perspectives from Southeast Asia. Forest Policy and Economics, 33(21-27).

Zachrisson, A., \& Lindahl, K. B. (2013). Conflict resolution through collaboration: Preconditions and limitations in forest and nature conservation controversies. Forest policy and economics, 33, 39-46. 